\title{
Plant-wide Assessment of High-Pressure Membrane Contactors in Natural Gas Sweetening - Part II: Process Analysis
}

\author{
Ven Chian Quek ${ }^{\mathrm{a}, \mathrm{b}}$, Nilay Shah ${ }^{\mathrm{a}}$, Benoît Chachuat ${ }^{\mathrm{a}, *}$ \\ ${ }^{a}$ Centre for Process Systems Engineering, Department of Chemical Engineering, Imperial College London, UK \\ ${ }^{b}$ Group Research $\mathcal{F}$ Technology, PETRONAS, Kuala Lumpur, Malaysia
}

\begin{abstract}
This paper presents a model-based assessment of a natural gas sweetening process combining high-pressure membrane contactor with conventional amine regeneration. The analysis builds on a mathematical model of the membrane contactor developed in the companion paper, which is capable of quantitative predictions of the $\mathrm{CO}_{2}$ and hydrocarbon absorption in the amine solvent and the solvent evaporative losses to the treated gas. The predictive capability of the plant-wide model is tested against data from a pilot plant operated under industrially relevant conditions at a natural gas processing facility in Malaysia, showing a close agreement of the predictions with the $\mathrm{CO}_{2}$ outlet purity and the energy consumption at various $\mathrm{CO}_{2}$ loading in the amine solvent. This enables a model-based analysis of various operational decisions on the plant-wide solvent losses and hydrocarbon recovery from the rich amine. A new semi-lean process configuration that replaces the energy-intensive stripper column by a simple flash separator is shown to reduce the overall energy consumption significantly while still meeting sales gas specification. This new configuration forms the basis for the scale-up of a commercial natural gas sweetening process, which shows a high intensification potential in terms of volume footprint and energy duty compared to conventional amine treating plants.
\end{abstract}

Keywords: membrane contactor, natural gas sweetening, high-pressure operation, process integration, semi-lean operation, experimental validation

\footnotetext{
${ }^{*}$ Corresponding author

Email address: b.chachuat@imperial .ac.uk (Benoît Chachuat)
} 


\section{Introduction}

Natural gas (NG) is a mixture of combustible hydrocarbon gases, that is typically composed of 70-90 vol\% methane plus other hydrocarbons such as ethane and propane, alongside impurities such as carbon dioxide $\left(\mathrm{CO}_{2}\right)$ and hydrogen sulfide $\left(\mathrm{H}_{2} \mathrm{~S}\right)$. High volumes of these impurities

5 can reduce the heating value of $\mathrm{NG}$, increase the compression cost for pipeline transport and increase the risk of corrosion, among other problems. For bulk $\mathrm{CO}_{2}$ removal the purity target is typically sales gas specification with a $\mathrm{CO}_{2}$ content below $2-3 \mathrm{~mol} \%$ [1]. For deep $\mathrm{CO}_{2}$ removal applications the purity specification is $50 \mathrm{ppmv}$ in liquefied natural gas (LNG) plants to avoid freezing in low-temperature chillers, and below $100 \mathrm{ppmv}$ in ammonia plants to prevent catalyst 10 poisoning [2, 3].

Membrane separation and chemical solvent absorption are both widely employed for NG sweetening [4, 5]. Membranes are attractive due to their potential for reducing physical footprint and capital and operating expenditures. However, current commercial membranes have a relatively low permeability and their low selectivity can lead to large hydrocarbon losses [6].

15 Chemical solvents, such as alkanolamines, can selectively react with the acid gases and thus minimize hydrocarbon losses. They are used extensively in absorption towers for deep $\mathrm{CO}_{2}$ removal, but this conventional technology incurs high capital expenditures, has a large physical footprint, and can be subject to operational problems [7, 8].

The membrane contactor (MBC) technology combines the advantages of both conventional

20 chemical absorption and membrane separation [9, 10]. Packaging into hollow-fiber membrane (HFM) modules offers a higher mass transfer area compared with conventional packed columns, giving MBC a high intensification potential [11-13]. This modularity also empowers a more flexible design and scale-up, while the ability to control the gas and liquid flow rates independently facilitates operations. The effectiveness of $\mathrm{MBC}$ for $\mathrm{CO}_{2}$ removal has been extensively

25 studied over the past few decades, including applications in $\mathrm{CO}_{2}$ post-combustion capture and NG sweetening [11, 12, 14]. A host of mathematical modeling studies have also been conducted to support these assessments, for MBC operating near atmospheric pressure [15-17] and at high pressure [18, 19], and to get a better understanding of the effect of membrane wetting on MBC performance [19, 20].

30 In principle, either or both of the absorber and stripper columns in a conventional amine treating process could be replaced with an MBC module. Yeon et al. [21] conducted an experimental assessment of a hybrid process combining an atmospheric-pressure MBC using amine solvent for $\mathrm{CO}_{2}$ removal from flue gas with a thermal stripping tower for the amine regeneration. They showed that this MBC-based process has a higher $\mathrm{CO}_{2}$ removal efficiency than with a conven-

${ }_{35}$ tional packed column and that the $\mathrm{CO}_{2}$ absorption rate per unit volume is 2 to 3 times higher with the MBC, thus confirming the intensification potential. Yan et al. [22] investigated a similar experimental set-up for the comparison of different absorbents. By contrast, Lee et al. [23] and Kosaraju et al. [24] studied a process not only employing an $\mathrm{MBC}$ for the $\mathrm{CO}_{2}$ absorption, but also for the desorption. Simons et al. [25], and more recently Kim et al. [26], used this coupled

40 $\mathrm{MBC}$ process for the separation of $\mathrm{CO}_{2}$ from methane in biogas and investigated the influence of the type of membrane and various process parameters on the overall process performance.

The usual key performance indicators (KPIs) for NG sweetening processes consist of: (i) the $\mathrm{CO}_{2}$ purity in the treated gas; and (ii) the energy per mass of $\mathrm{CO}_{2}$ removed. From a technoeconomic standpoint, other relevant KPIs include: (iii) the fraction of hydrocarbons lost via

45 absorption in the amine solution; and (iv) the amount of solvent evaporative losses per volume of treated gas. Mathematical models can provide an effective tool to quantify these KPIs, and in 
turn enable a better assessment and optimization of the whole process performance. But unlike modeling studies for stand-alone MBC modules, detailed models for the plant-wide simulation of MBC-based processes are still lacking. Recently, Pakšiová et al. [27] modeled a coupled

$50 \mathrm{MBC}$ process operating at atmospheric pressure for both the separation of $\mathrm{CO}_{2}$ from methane by absorption and the stripping of $\mathrm{CO}_{2}$ from the amine solution. Although simplifying modeling assumptions based on mass transfer coefficient and non-wetted operation were made to describe the two MBC units, the plant-wide model could be used to analyze the effects of different liquid and gaseous flow rates on the overall energy consumption. To the best of the authors' knowledge

55 however, there is no published literature on plant-wide modeling of MBC-based processes for NG sweetening that would simultaneously consider all four above-mentioned KPIs.

The present paper addresses this gap by conducting a model-based analysis of an MBCbased process for NG sweetening. The process of interest is akin to a traditional amine treating process where the absorber column is simply replaced with an MBC. The enriched amine solvent

60 from the MBC is regenerated by stripping the absorbed hydrocarbons and acid gases, before returning it to the $\mathrm{MBC}$ inlet. Both lean and semi-lean operations are possible in this process configuration depending on how much $\mathrm{CO}_{2}$ remains in the amine solvent after its regeneration. Because solvent regeneration is the most energy intensive part [8, 28], the semi-lean operation can reduce the operating cost significantly yet to the detriment of $\mathrm{CO}_{2}$ abatement. The benefit of

65 using a high-pressure MBC rather than a conventional packed column for the $\mathrm{CO}_{2}$ absorption is also a reduction in liquid-to-gas (L/G) ratio [29], which translates into less solvent to regenerate. The overall energy consumption may be further reduced by burning the light hydrocarbon gas recovered from the enriched amine solution, provided that it is compliant with the calorific value of fuel gas. Solvent make-up is furthermore needed to compensate for the evaporative losses due 70 to both $\mathrm{CO}_{2}$ absorption and stripping operations.

In order to conduct the techno-economic assessment, we develop a plant-wide model using the advanced process modelling platform gPROMS ${ }^{\circledR}$ [30], which builds on the MBC model presented in the companion paper [31]. This MBC model uses a combination of 1-d and 2$\mathrm{d}$ mass-balance equations to predict the $\mathrm{CO}_{2}$ absorption flux and membrane wetting for both

75 lean and semi-lean amine solutions, and it has a unique capability for predicting the $\mathrm{CO}_{2}$ and hydrocarbon absorption in the amine solvent and the solvent evaporative losses to the treated gas for a wide range of gas and solvent flowrates. We test the predictive capability of the plant-wide model against data from a pilot plant operated under industrially relevant conditions at a natural gas processing facility in Malaysia, and then use it to conduct process analysis and scale-up.

The rest of the paper is organized as follows. The experimental set-up of the pilot-scale MBC is described in Sec. 2 along with the corresponding plant-wide model and its implementation in gPROMS. Results of the experimental model verification are presented and discussed in Sec. 3 . A model-based analysis is conducted in Sec. 4, where the effect of operational decisions on hydrocarbon recovery and solvent losses are investigated and two process configurations for lean

85 and semi-lean operations are compared in terms of energy duty. The design and scale-up of a commercial-scale MBC under semi-lean operations is conducted in Sec. 5] and its intensification potential is assessed. Finally, Sec.6 concludes the paper.

\section{Material and Methods}

\subsection{Pilot Plant Setup}

90 Experiments were conducted on a pilot plant at a NG processing facility in Malaysia. The $\mathrm{CO}_{2}$-rich natural gas with up to $18 \mathrm{~mol} \% \mathrm{CO}_{2}$ was produced by blending pure $\mathrm{CO}_{2}$ from pres- 


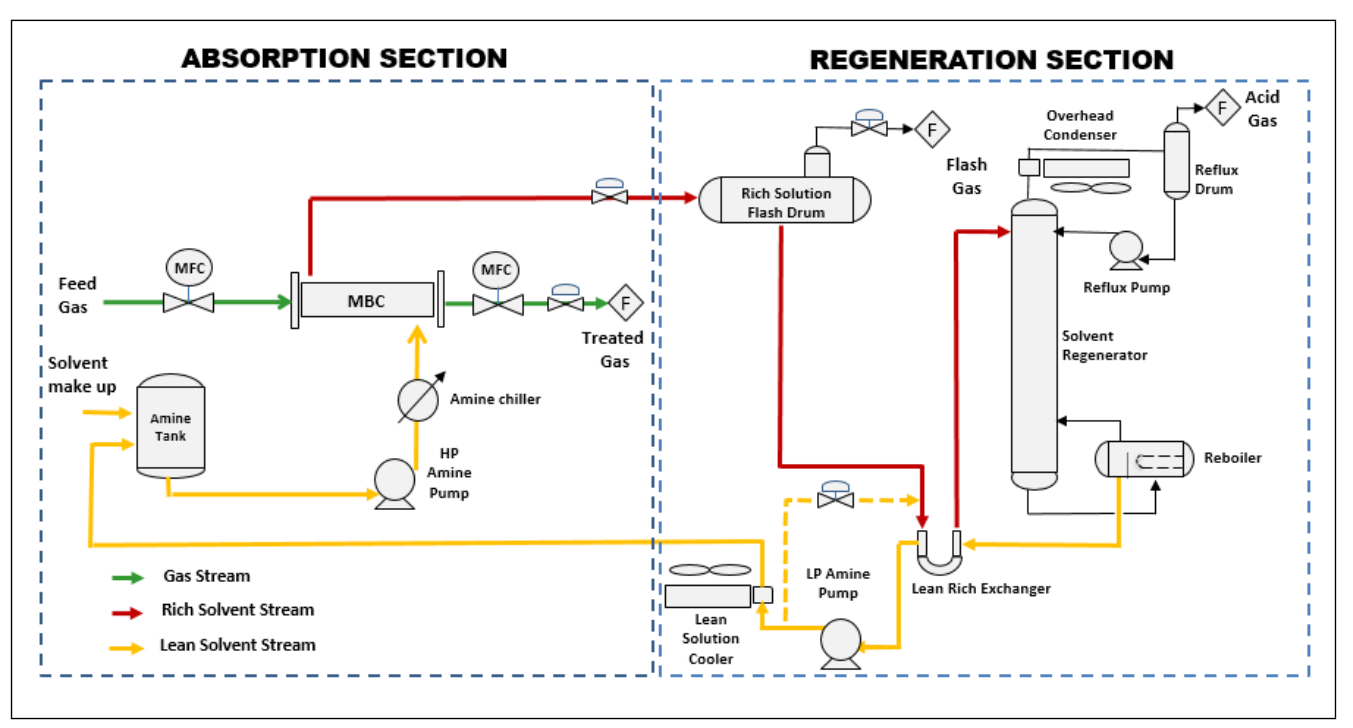

Figure 1: Diagram of the pilot plant setup.

surized gas cylinders into the NG feed stream, and a liquid-Gas coalescer was used to remove any water or hydrocarbon liquids. An aqueous mixture of methyldiethanolamine (MDEA) and piperazine (PZ) was used as the chemical solvent. The experimental setup is depicted on Fig. 1

The $\mathrm{CO}_{2}$-rich natural gas is fed to the tube side of the $\mathrm{MBC}$ at 54 bar, while the lean solvent is fed to the shell side also at a pressure of ca. 54 bar, in a counter-current and horizontal configuration. Circulating the solvent in the shell section of the MBC (instead of tube section) reduce the pressure drops significantly, while operating the MBC horizontally removes the need to overcome the static head and reduces membrane wetting [19]. The feed gas and solvent flow rates

100 are controlled using a mass-flow controller (MFC) and pump stroke, respectively. The enriched amine solvent collected from the MBC shell outlet is directed to the rich-solution flash drum for degassing of the dissolved light hydrocarbons. The flashed liquid outlet stream is heated by cross exchange with hot lean solvent before feeding into the regenerator column where it is stripped of acid gas by a rising stream of vapors generated by the electrical reboiler. The acid gas leaving the 105 top of this stripper column is cooled and feeds into the reflux drum for separating the condensed water from the acid gas. The condensed water is then returned to the top of the column, while the acid gas is flared. The lean solvent from the regenerator is cooled by passing through the lean-rich exchanger, then the lean solution cooler, and finally the amine chiller, before returning to the MBC. Since the solvent regenerator was designed for a maximal capacity 10-times

110 larger than the MBC module, about $88 \%$ of the regenerated solvent is mixed with the rich amine and returned to the stripper-connection downstream of the LP amine pump shown in dashed line on Fig. 1. Both demineralized water and fresh MDEA and PZ are fed into the amine tank periodically to make up for evaporative solvent losses in the MBC and the stripper column.

The gas flowrates at the outlet of the MBC and of the flash drum were measured with a mass 115 flowmeter. The gas compositions at the inlet and outlet of the MBC and at the outlet of the flash drum were analyzed using a gas chromatograph (PGC1000, ABB). These measurements were recorded over several hours of steady-state operation and averaged to filter out the noise. The 
Table 1: Packing material and properties of stripper column.

\begin{tabular}{lrc}
\hline Property & Value & Source \\
\hline Packing height / diameter $(\mathrm{m})$ & $6.1 / 0.3$ & Manufacturer \\
Packing size $(\mathrm{m})$ & 0.025 & Manufacturer \\
Surface area $\left(\mathrm{m}^{-1}\right)$ & 150 & Manufacturer \\
Void fraction $(-)$ & 0.98 & Manufacturer \\
\hline Loading point constant, $C_{\mathrm{s}}(-)$ & 3.491 & {$[32$} \\
Flooding point constant, $C_{\mathrm{FL}}(-)$ & 2.2 & {$[32]$} \\
Hydraulic constant, $C_{\mathrm{h}}(-)$ & 0.75 & {$[32]$} \\
Total particles constant, $C_{\mathrm{P} 0}(-)$ & 0.5 & {$[32$} \\
Liquid constant, $C_{\mathrm{L}}(-)$ & 1.29 & {$[32]$} \\
Vapor constant, $C_{\mathrm{v}}(-)$ & 0.44 & {$[32$} \\
\hline
\end{tabular}

$\mathrm{CO}_{2}$ loading in the enriched and regenerated amine solvents were measured by titration during steady-state operation 11 All of the pieces of equipment in the pilot plant are electrically powered.

120 The power consumption of the reboiler, overhead condenser, reflux pump, LP amine pump, lean solution cooler, HP amine pump, and amine chiller were monitored and added to obtain the total power consumption, also referred to as the process duty below.

The high pressure MBC module was packed with hydrophobic, polytetrafluoroethylene (PTFE) hollow fiber, with a steel tube insert at the center of the module to artificially reduce the specific membrane area. The main characteristics of these membranes and the geometrical properties of the MBC module are reported in the companion paper [31]. The stripper column was packed with Raschig Super-Ring No. 1 (RASCHIG GMBH). The properties of this packing material are listed in the top part of Table 1 .

\subsection{Pilot Plant Modeling}

A plant-wide model of the pilot plant was developed using gPROMS ProcessBuilder (v1.3.1) and compiled into a gPROMS Model Library (gML) with the interface shown in Fig. 2. It was then combined with unit models of the solvent regeneration operations from both the standard and advanced gML, resulting in the process flowsheet displayed in Fig. 3 The corresponding operating conditions are summarized in Table 2 and further modeling details about the MBC, the stripper column, flash drum, heat exchangers and pumps are given next. All of the physical properties for the solvent regeneration operations are estimated using the RKSA equation of state, as available via the interface between gPROMS and Multiflash (v6.1).

${ }^{1}$ The $\mathrm{pH}$ of $125 \mathrm{~mL}$ of methanol was first adjusted to 11.2 by adding $0.5 \mathrm{~N} \mathrm{KOH}$ in a beaker. $20 \pm 0.5 \mathrm{~g}$ of amine solvent was then transferred into the beaker, and the solution was titrated with $0.5 \mathrm{~N} \mathrm{KOH}$ until reaching $\mathrm{pH} 11.2 \pm 0.02$ again. The same procedure was repeated on a fully regenerated amine (overnight reflux). The $\mathrm{CO}_{2}$ content (wt\%) and $\mathrm{CO}_{2}$ loading $\left(\mathrm{mol} \mathrm{mol}^{-1}\right)$ were calculated as:

$$
\begin{aligned}
& \mathrm{CO}_{2} \text { content }=\left(\frac{V_{1}}{m_{1}}-\frac{V_{2}}{m_{2}}\right) N M W_{\mathrm{CO}_{2}} \\
& \mathrm{CO}_{2} \text { loading }=\frac{\mathrm{CO}_{2} \text { content }}{M W_{\mathrm{CO}_{2}}} \frac{M W_{\text {amine }}}{\text { amine content }}
\end{aligned}
$$

with $V_{1}(\mathrm{~L})$ and $m_{1}(\mathrm{~g})$ the volume and mass of $\mathrm{KOH}$ used to titrate the amine solvent; $V_{2}(\mathrm{~L})$ and $m_{2}(\mathrm{~g})$ the volume and mass of $\mathrm{KOH}$ used to titrate the fully-regenerated amine solvent; $N$ the $\mathrm{KOH}$ normality $\left(\mathrm{mol} \mathrm{L}{ }^{-1}\right) ; M W_{\mathrm{CO}_{2}}$ the molecular weight of $\mathrm{CO}_{2} ; M W_{\text {amine }}$ the average molecular weight of MDEA and PZ; and the amine content as given in Table 2 
Table 2: Nominal operating conditions in the pilot experimental setup.

\begin{tabular}{|c|c|}
\hline \multicolumn{2}{|l|}{ Absorption - NG sweetening } \\
\hline MBC tube, inlet gas composition $\mathrm{CO}_{2} / \mathrm{CH}_{4} / \mathrm{C}_{2} \mathrm{H}_{6} / \mathrm{C}_{3} \mathrm{H}_{8}(\mathrm{~mol} \%)$ & $5 / 85 / 7 / 3$ \\
\hline inlet gas flowrate $\left(\mathrm{kg} \mathrm{h}^{-1}\right)$ & 75 \\
\hline inlet gas pressure $(\mathrm{kPa})$ & 5400 \\
\hline inlet gas temperature $(\mathrm{K})$ & 298 \\
\hline MBC shell, inlet solvent composition MDEA / PZ (wt\%) & $39 / 5$ \\
\hline inlet solvent flowrate $\left(\mathrm{L} \mathrm{h}^{-1}\right)$ & 275 \\
\hline inlet solvent temperature $(\mathrm{K})$ & $303-308$ \\
\hline outlet solvent pressure $(\mathrm{kPa})$ & 5430 \\
\hline inlet $\mathrm{CO}_{2}$ loading in solvent $\left(\mathrm{mol} \mathrm{mol}^{-1}\right)$ & $0.01-0.23$ \\
\hline \multicolumn{2}{|l|}{ Desorption - Solvent regeneration } \\
\hline Rich solution drum pressure $(\mathrm{kPa})$ & 911 \\
\hline Solvent regenerator pressure $(\mathrm{kPa})$ & 258 \\
\hline Reboiler temperature $(\mathrm{K})$ & $376-403$ \\
\hline Overhead condenser, outlet temperature $(\mathrm{K})$ & 333 \\
\hline Reflux pump, outlet pressure $(\mathrm{kPa})$ & 258 \\
\hline Lean-rich exchanger cold stream, outlet temperature $(\mathrm{K})$ & 371 \\
\hline outlet pressure $(\mathrm{kPa})$ & 368 \\
\hline hot stream, outlet pressure $(\mathrm{kPa})$ & 233 \\
\hline LP amine pump, outlet pressure $(\mathrm{kPa})$ & 711 \\
\hline Lean solution cooler, outlet temperature $(\mathrm{K})$ & 318 \\
\hline pressure drop $(\mathrm{kPa})$ & 35 \\
\hline HP amine HP pump, outlet pressure $(\mathrm{kPa})$ & 5460 \\
\hline Amine chiller, outlet temperature $(\mathrm{K})$ & $303-308$ \\
\hline pressure drop $(\mathrm{kPa})$ & 30 \\
\hline
\end{tabular}




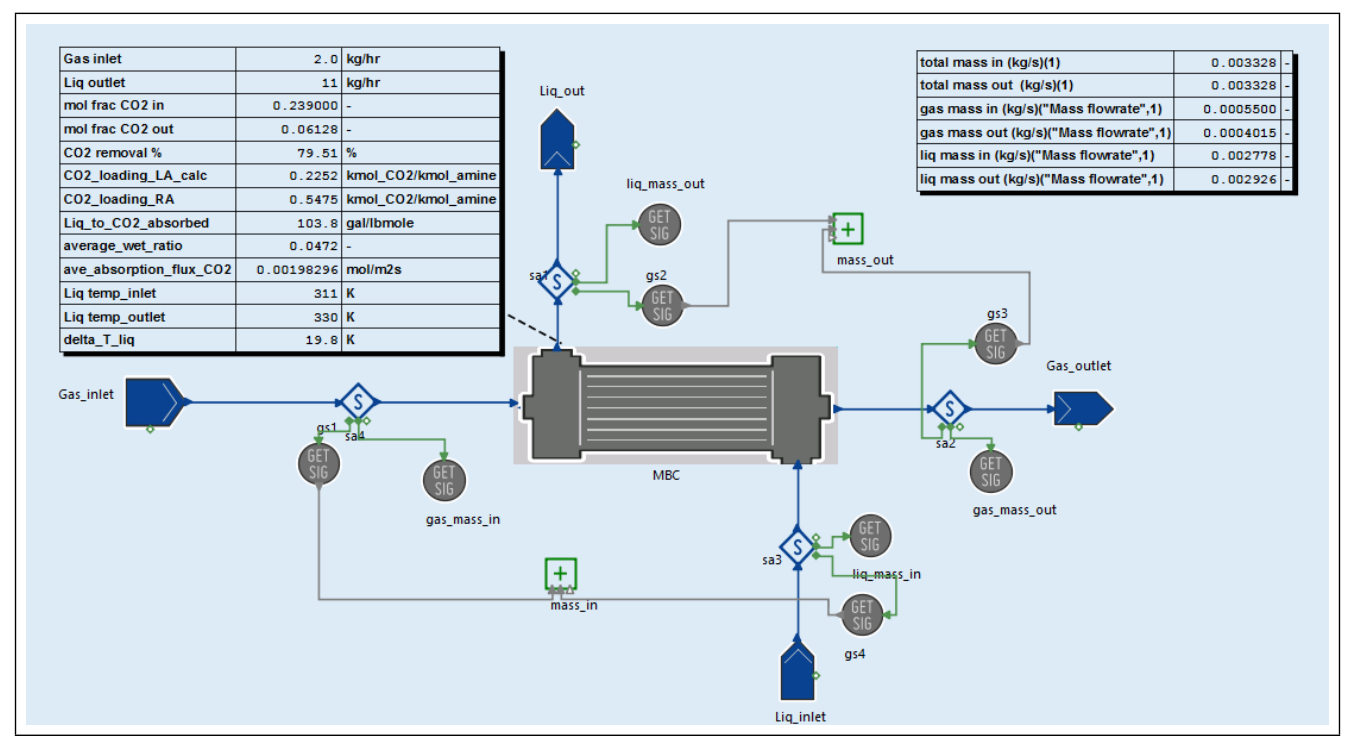

Figure 2: gML-compliant unit operation model of MBC module in gPROMS ProcessBuilder.

Modeling of Membrane Contactor. The MBC model uses a combination of 1-d and 2-d massand energy-balance equations to predict (i) the $\mathrm{CO}_{2}$ absorption flux and membrane wetting under lean solvent operation under both lean and semi-lean operations, (ii) the exothermic absorption of $\mathrm{CO}_{2}$ into the solvent and the evaporative losses of water and amines with the treated gas, and (iii) the absorptive losses of light hydrocarbons with the solvent. A complete description of this model can be found in the companion paper [31].

Modeling of Stripper Column. The rate-based model of gas-liquid contactor from the advanced $145 \mathrm{gML}$ is used, where mass and heat exchange between the bulk gas and liquid films is described by means of an infinitely thin interface with the phases at equilibrium. Built-in correlations are used to predict the performance of the Raschig Super-Ring No. 1 packing (bottom part of Table 1), specifically: the Onda correlations for mass transfer with random packing to predict the mass transfer coefficients and the interfacial area; and the Billet holdup correlation to calculate the liquid holdup in the regenerator. The column operates at a pressure of $258 \mathrm{kPa}$ and pressure drops are neglected in first approximation. This main gas-liquid contactor model is coupled with models of the reboiler and overhead condenser. The condenser is modeled as a standard separator, with outlet temperature set to $333 \mathrm{~K}$ in order for the fluid to separate into two phases. The reboiler is described by an evaporator kettle model, where the temperature is in the range between $376-403 \mathrm{~K}$ in order to achieve either lean or semi-lean operation. The complete model of the stripper column predicts the flow rate, composition, temperature and pressure of both the outlet gas and lean solvent streams, as well as the power consumption corresponding to the heating and cooling utilities.

Modeling of Rich-Solution Flash Drum. This unit is modeled as a phase separator, where the 160 pressure of the enriched amine solution is reduced to $911 \mathrm{kPa}$. An adiabatic separator model from the standard gML is used to predict the flow rate, composition and temperature of both the outlet gas and liquid streams. 


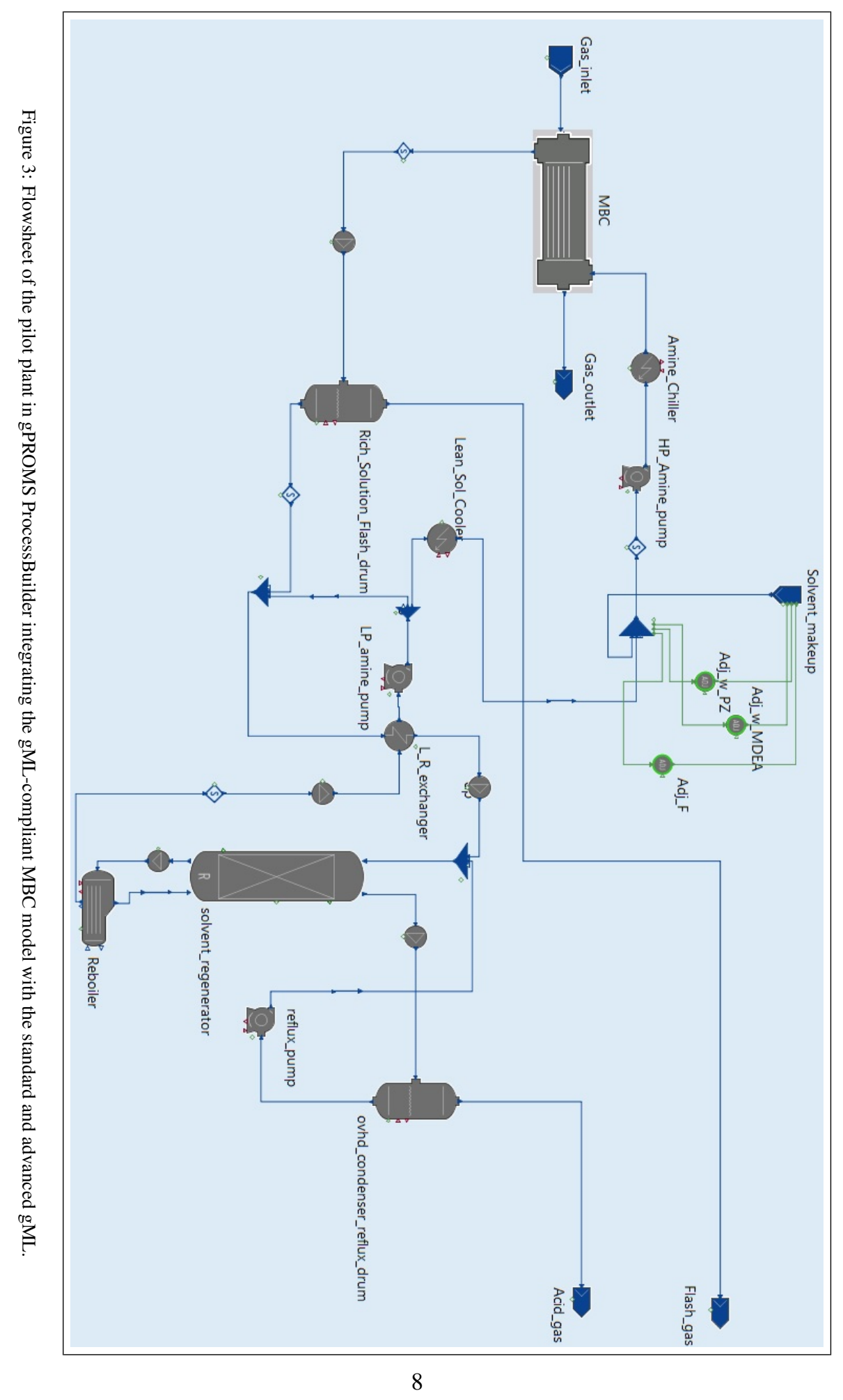


Modeling of Heat Exchangers. The process flowsheet comprises three heat exchangers-leanrich heat exchanger, lean solution cooler, and amine chiller. The lean-rich heat exchanger is modeled as a two-stream countercurrent heat exchanger from the standard gML, with a specification on the outlet temperatures of the rich amine (cold stream) of $371 \mathrm{~K}$. Both the lean solution cooler and the amine chiller are modeled as simple cooler elements in the standard gML, with a small pressure drop. The specification on the outlet temperature of the lean solution cooler is $318 \mathrm{~K}$, while the outlet temperature of the amine chiller is set to the desired inlet solvent temperature, here in the range between 303-308 K. Both cooler models predict the power consumption required to meet these thermal specifications.

Modeling of Pumps. All three pumps in the process flowsheet-amine HP pump, amine LP pump, and reflux pump - are assumed to have mechanical and isentropic efficiencies of $85 \%$. The model predicts the power consumption of each pump in order to meet the specified outlet pressures (see Table 2). The temperature of the pump outlet stream is furthermore calculated by defining the fluid compression relative to an ideal compression process, using an ideal efficiency.

Modeling of Solvent Make-up. The desired flowrate and composition of the amine solution in the $\mathrm{MBC}$ are set using three separate control elements: one for adjusting the flowrate to $275 \mathrm{Lh}^{-1}$; the other two for adjusting the mass fractions of MDEA and PZ to $39 \mathrm{wt} \%$ and $5 \mathrm{wt} \%$, respectively. The outlet streams from the control elements are mixed together with the regenerated amine solution before feeding into the MBC unit.

\subsection{Numerical Simulation}

The numerical discretization approach used to implement the MBC model was described in the companion paper [31]. In order to reduce the computational burden, a coarser uniform mesh grid consisting of 35 elements - compared with 70 elements previously — was adopted to perform the plant-wide simulations, which still provides solutions within $2 \%$ of finer discretizations. For the solvent regenerator, a first-order finite difference scheme was applied to both the bulk liquid and vapor phases. With these settings, a steady-state simulation takes about 10 minutes to run on a desktop computer running Windows 7 with Intel ${ }^{\circledR} \mathrm{Core}^{\mathrm{TM}} \mathrm{i} 7-4790 \mathrm{CPU}$ at $3.60 \mathrm{GHz}$ and $32 \mathrm{~GB}$ of RAM.

\section{Experimental Plant-wide Model Verification}

Predictions of the plant-wide model in terms of $\mathrm{CO}_{2}$ removal in the $\mathrm{MBC}, \mathrm{CO}_{2}$ loading in both the enriched and regenerated amine solutions, and total process duty are compared against experimental data from the pilot plant in Fig. 4. All of these experiments were conducted at constant gas $\left(75 \mathrm{~kg} \mathrm{~h}^{-1}\right)$ and solvent $\left(275 \mathrm{~L} \mathrm{~h}^{-1}\right)$ flow rates by varying the reboiler temperature in the stripper column, which resulted in different $\mathrm{CO}_{2}$ loadings in the regenerated amine solutionadditional experiments conducted for different $\mathrm{L} / \mathrm{G}$ ratios in the $\mathrm{MBC}$ can be found in the companion paper [31].

Overall, the model predictions are in excellent agreement with the experimental data. Prediction errors are within 5\% for the $\mathrm{CO}_{2}$ absorption flux (Fig. 44 ), the $\mathrm{CO}_{2}$ removal efficiency (Fig. 43 , right axis), the $\mathrm{CO}_{2}$ loading in both the enriched and regenerated amine solutions (Fig. 4C), and the total process duty (Fig. 4D). Notice the somewhat larger prediction error for the outlet $\mathrm{CO}_{2}$ molar fraction (Fig. 43 , left axis) - e.g., the prediction error close to $15 \%$ for 

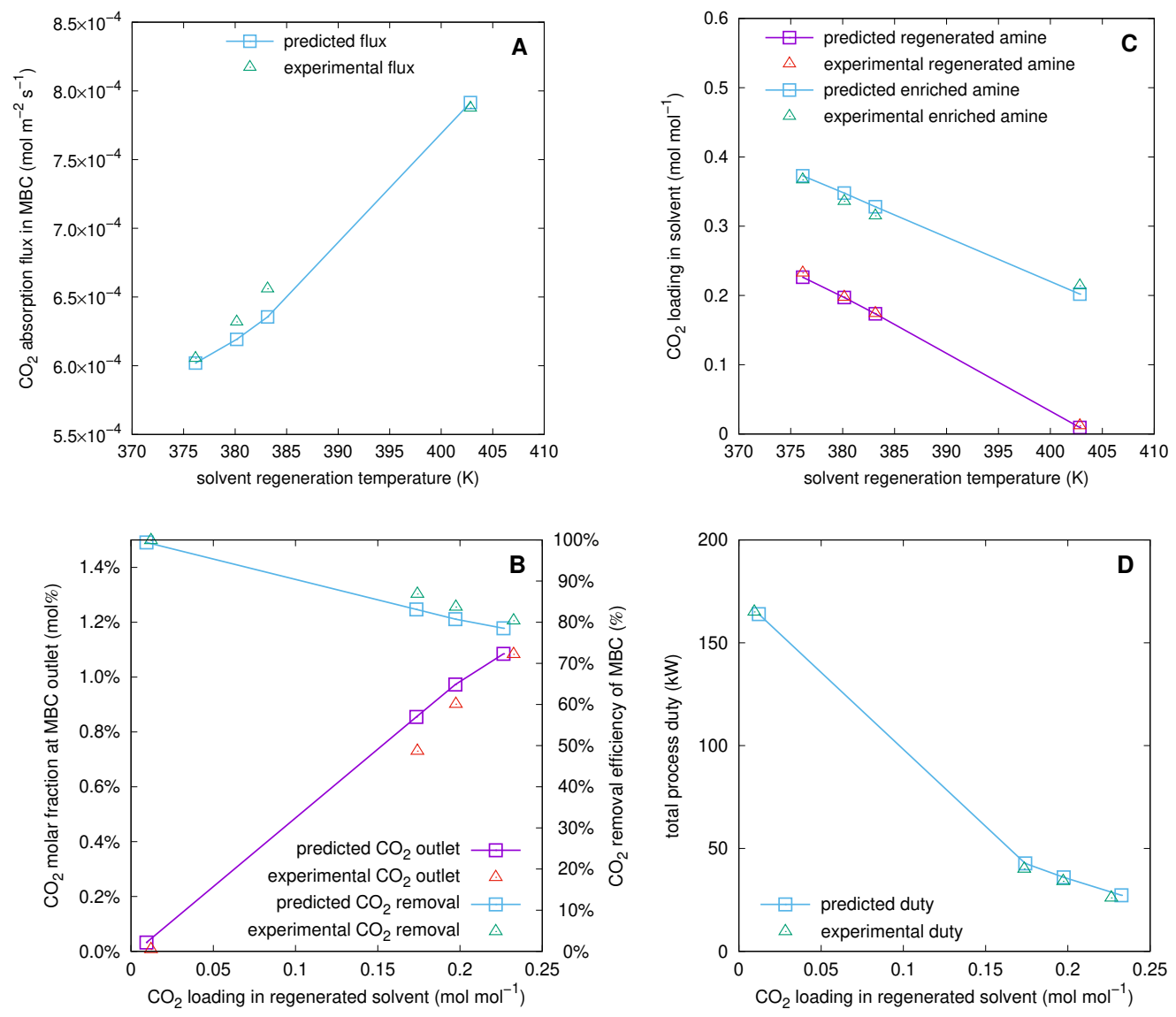

Figure 4: Comparison of plant-wide model predictions against experimental data from the pilot plant with a gas flowrate of $75 \mathrm{~kg} \mathrm{~h}^{-1}$ and solvent flowrate of $275 \mathrm{~L} \mathrm{~h}^{-1}$. A: $\mathrm{CO}_{2}$ absorption flux in $\mathrm{MBC}$ at various solvent regeneration temperatures; $\mathbf{B}$ : $\mathrm{CO}_{2}$ purity at $\mathrm{MBC}$ gas outlet and $\mathrm{CO}_{2}$ removal efficiency at various $\mathrm{CO}_{2}$ loadings in amine solvent; $\mathbf{C}$ $\mathrm{CO}_{2}$ loading levels at various solvent regeneration temperatures; $\mathbf{D}$ : total process duty at various $\mathrm{CO}_{2}$ loadings in amine solvent. 
the second experimental point—which is nonetheless acceptable given the relatively low $\mathrm{CO}_{2}$ concentration at the MBC outlet.

The capability of the MBC model to make quantitative predictions of the $\mathrm{CO}_{2}$ removal efficiency under both lean and semi-lean conditions (Fig. 43) was discussed in the companion paper [31], where an increase in $\mathrm{CO}_{2}$ loading of the amine solution can reduce the absorption flux by $20 \%$ or more. In order to achieve deep $\mathrm{CO}_{2}$ removal, in particular to meet the LNG specification 210 of 50 ppmv, operating the MBC with a regenerated lean amine is necessary. On the other hand, operation with a regenerated semi-lean amine appears to be sufficient to meet the typical sales gas specification of $2-3 \mathrm{~mol} \% \mathrm{CO}_{2}$.

On top of this, the plant-wide model correctly describes the effect of reducing the solvent regeneration (reboiler) temperature on increasing the $\mathrm{CO}_{2}$ loading in the regenerated amine

215 (Fig. 4C), which in turn decreases the $\mathrm{CO}_{2}$ absorption flux in the MBC (Fig. 4A). Notice, in particular, how accurately the model describes the difference in $\mathrm{CO}_{2}$ loading between the enriched and regenerated solvents, which narrow down as the reboiler temperature is lowered. The corresponding reduction in heating and cooling duties is accurately predicted, too (Fig. 4P).

These experimental data suggest that the energy consumption for meeting sales gas specifica-

220 tion (2-3 mol\% $\mathrm{CO}_{2}$ ) could be reduced dramatically, by up to $80 \%$, upon operating the pilot plant with a semi-lean solvent (regeneration temperature of $376 \mathrm{~K}$ ) instead of a lean solvent (regeneration temperature of $423 \mathrm{~K}$ ). This observation is consistent with previous studies by Alie [33] and $\mathrm{Xu}$ et al. [34], which reported significant reductions in the reboiler duty upon increasing the $\mathrm{CO}_{2}$ loading of the regenerated amine to $0.2 \mathrm{~mol} \mathrm{~mol}^{-1}$ or higher. The plant-wide model is used

225 to further this analysis in Sec. 4 , before investigating the scale-up of a semi-lean MBC-based process of NG sweetening under industrially-relevant conditions in Sec. 5

\section{Model-based Analysis of Pilot Setup}

\subsection{Process-wide Solvent Losses}

Although the amine solvent is not consumed during the acid gas removal process, losses via evaporation or entrainment are inevitable. Unlike conventional packed columns, solvent entrainment cannot occur in MBC because the microporous membrane prevents the dispersion of the gas and liquid phases into one another. However, water, MDEA or PZ losses may still occur with the treated gas, flash gas and acid gas streams. These losses are dependent on the type and concentration of amine, but also on the operating temperature and pressure of the MBC,

235 flash drum and stripper column from a process-wide viewpoint (cf. Fig. 1). The solvent makeup stream compensates for such losses by maintaining a desired solvent amount and composition in the process.

Predictions of the evaporative solvent losses across the entire NG sweetening process are presented in Fig. 5 for the same gas and solvent flowrates as in the experimental verification above.

240 Notice that the water evaporative losses are 100-fold larger than the PZ losses, which are themselves 2-3 times larger than the MDEA losses, in agreement with their respective vapor pressures. Interestingly, varying the reboiler temperature in the stripper column shows an opposite effect on the total water losses and on the total amine losses (Fig. 5A). The water losses increase by over $20 \%$ in raising the reboiler temperature from $376 \mathrm{~K}$ to $403 \mathrm{~K}$, whereas the amine losses are about

245 halved at the same time. This counter-intuitive behavior-one would expect the amine losses to increase with the reboiler temperature instead-is attributed to non-ideality and association effects in the water-MDEA-PZ mixture. It could be reproduced with different thermodynamic 

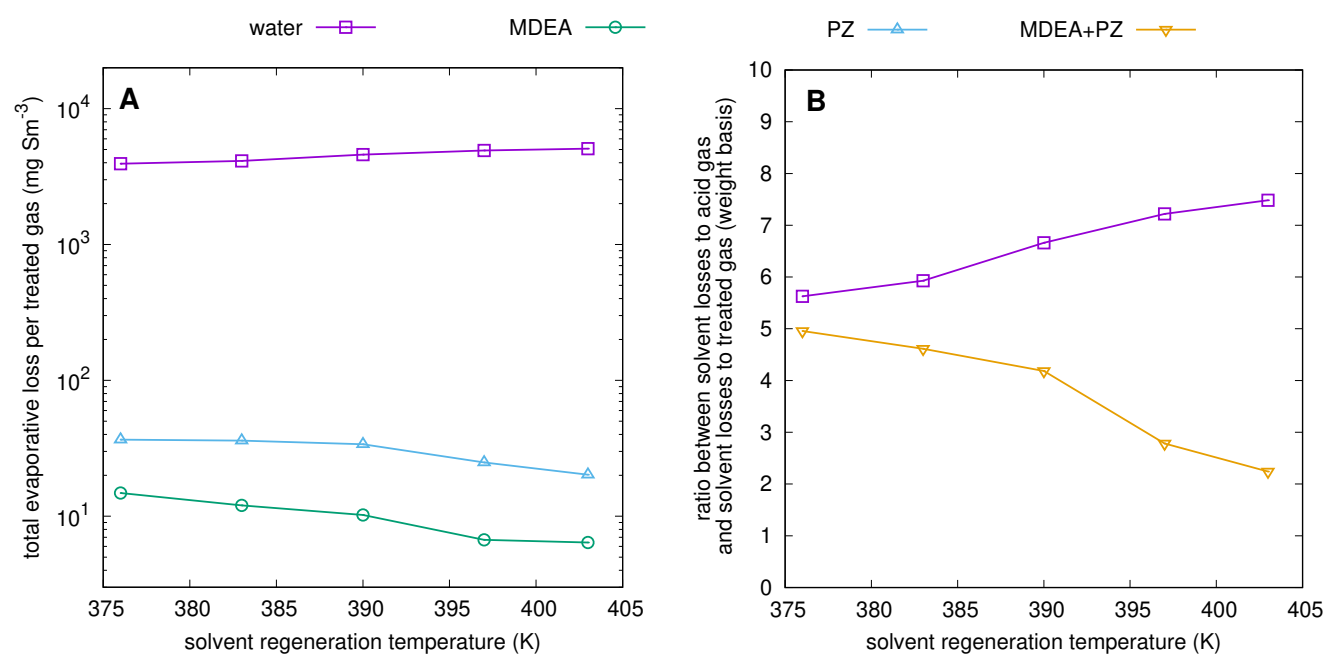

Figure 5: Effect of solvent regeneration temperature in stripper column on process-wide evaporative losses, with a gas flowrate of $75 \mathrm{~kg} \mathrm{~h}^{-1}$ and solvent flowrate of $275 \mathrm{~L} \mathrm{~h}^{-1}$. A: water and amine losses per volume of treated gas; $\mathbf{B}$ : comparison of solvent losses in treated gas and acid gas streams.

property packages in gPROMS, including RKSA and SAFT-VR, but the process model predictions could be subject to large errors due to the low residual concentrations of MDEA and PZ in the acid gas. A breakdown of these losses reveals that: (i) evaporative losses with the flash gas contribute only $1-3 \%$ of the overall losses; (ii) evaporative losses with the treated gas show very little variations (2-4\%) over the reboiler temperature range of interest; and (iii) both the water and amine losses with the acid gas make by far the largest share (70-90\%) of the evaporative losses in the process (Fig. $5 \mathrm{~B}$ ). This latter observation suggests that a reduction in the overhead condenser temperature, for instance from $333 \mathrm{~K}$ to $318 \mathrm{~K}$, could significantly curtail the overall water and amine losses. In practice, it is also expected that more MDEA and PZ will be conveyed upwards through mist entrainment than strictly as vaporization losses [35], which are not accounted for in the stripper model. The use of MBC technology to replace the stripper column could help further reduce solvent losses, by preventing such entrainment losses.

The total amine (MDEA + PZ) losses in the pilot plant are predicted to be between 27 $54 \mathrm{mg}$ per $\mathrm{Sm}^{3}$ of treated gas, which is commensurate with reported average amine losses of ca. $48 \mathrm{mg} \mathrm{Sm}^{-3}$ ( $3 \mathrm{lb} \mathrm{MMSCF}^{-1}$ ) in existing gas processing plants using monoethanolamine (MEA), diethanolamine (DEA) and MDEA [35]. The predicted amine losses per $\mathrm{CO}_{2}$ removed are between $0.24-0.63 \mathrm{~kg} \mathrm{ton}^{-1}$, which is again consistent with conventional NG sweetening plants $265 \quad\left(0.35-3 \mathrm{~kg} \mathrm{ton}^{-1}\right)$ [7, 36].

In the current setup, the total solvent losses amount to about $0.1-0.15 \%$ of the solvent circulation rate $\left(275 \mathrm{~L} \mathrm{~h}^{-1}\right)$ and water makes over $99 \mathrm{wt} \%$ of these losses. This suggests that pure water makeup should be sufficient to maintain the solvent concentration during normal operations, complemented with regular injection of fresh amine into the process when the amine inventory has dropped below a certain threshold or has thermally degraded. 

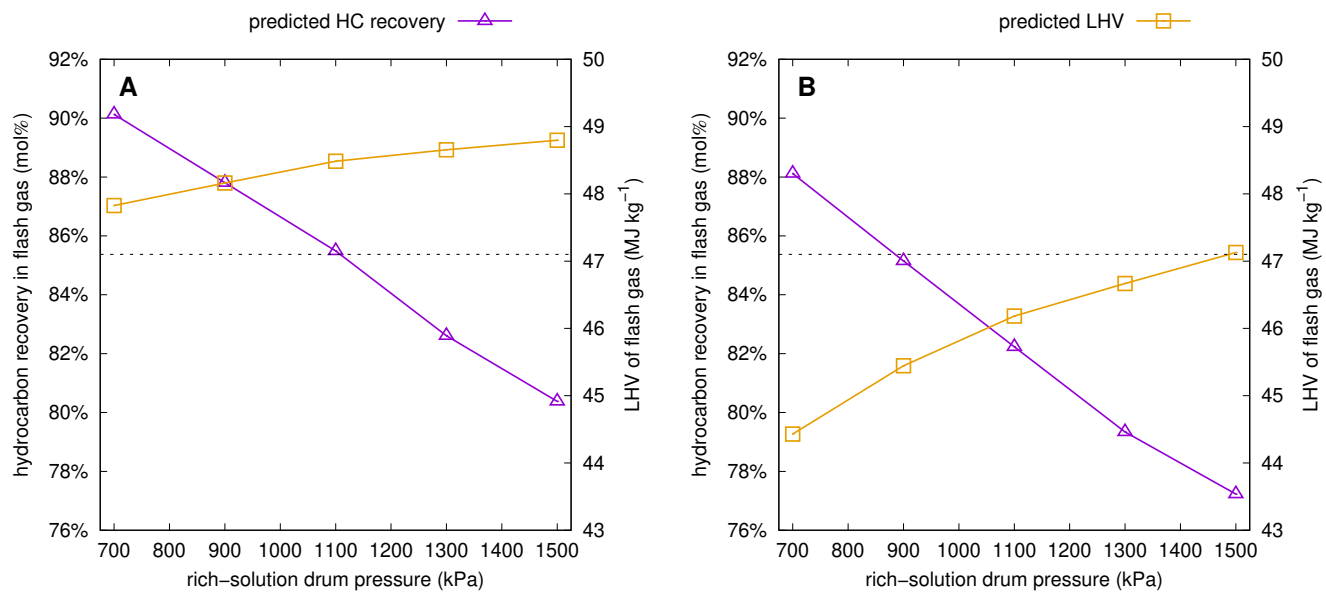

Figure 6: Effect of pressure in rich solution flash drum on hydrocarbon recovery and LHV of flash gas, with a gas flowrate of $75 \mathrm{~kg} \mathrm{~h}^{-1}$ and solvent flowrate of $275 \mathrm{~L} \mathrm{~h}^{-1}$. A: lean amine operation (inlet $\mathrm{CO}_{2}$ loading: 0.01); B: semi-lean amine operation (inlet $\mathrm{CO}_{2}$ loading: 0.23). Dotted line: lower limit of NG fuel gas specification.

\subsection{Process-wide Hydrocarbon Losses}

Hydrocarbons absorbed alongside $\mathrm{CO}_{2}$ by the solvent might end up in the acid gas stream if they are not recovered. Although these losses are typically a tiny fraction of the treated gas, they could add up to a large economic loss and cause problems in the downstream processing of the acid gas [37]. A large fraction of these hydrocarbons may be recovered in the rich solution flash drum downstream of the MBC liquid outlet (Fig. 1). It is customary to use the flash gas in a gas turbine for heat recovery. A usual specification for the fuel gas is based on the lower heating value (LHV) of $47.1 \mathrm{MJ} \mathrm{kg}^{-1}$ for NG [38], although specially-designed gas turbines may still be used for $\mathrm{NG}$ with higher $\mathrm{CO}_{2}$ content and lower LHV [39]. Alternatively, the flash gas could be compressed and returned to the $\mathrm{MBC}$ gas inlet, or simply mixed with the treated gas subject to meeting the required $\mathrm{CO}_{2}$ purity.

Adjusting the operating pressure of the rich solution flash drum provides an effective strategy to mitigating hydrocarbon losses. The results of a case study that considers the same gas and solvent flowrates as before are shown in Fig. 6, for both lean and semi-lean conditions. The hydrocarbon recovery is calculated on a mole basis with respect to the hydrocarbon content of the MBC liquid outlet. The LHV of the flash gas is calculated based on the LHV of methane, ethane and propane [40], weighted by their respective mass fractions and using an LHV of zero for $\mathrm{CO}_{2}$. From thermodynamic considerations, operating the rich solution flash drum at a lower pressure increases the amount of flash gas, thereby increasing fuel gas recovery. But those species with a lower vapor pressure, such as $\mathrm{CO}_{2}$, also flash off of the amine solvent at lower pressure, thereby reducing the LHV of the flash gas. This defines a clear trade-off in terms of the flash drum pressure.

Upon reducing the rich solution flash drum pressure from $1500 \mathrm{kPa}$ to $700 \mathrm{kPa}$, the predicted hydrocarbons recovery increases from about $81 \%$ to $90 \%$ under lean conditions (Fig. 6A) and from $77 \%$ to $88 \%$ under semi-lean conditions (Fig. 6B). Under lean conditions, the flash gas meets the LHV specification of $47.1 \mathrm{MJ} \mathrm{kg}^{-1}$ (dotted line) at all pressure values, with a corresponding maximal recovery of over $90 \%$ at $700 \mathrm{kPa}$. By contrast, the LHV of the flash gas only 
reaches $47.1 \mathrm{MJ} \mathrm{kg}^{-1}$ at $1500 \mathrm{kPa}$, yet with a much lower recovery of $77 \%$. This higher $\mathrm{CO}_{2}$ content is due to a richer amine under semi-lean conditions $\left(0.37 \mathrm{~mol} \mathrm{~mol}^{-1}\right.$ at $\mathrm{MBC}$ liquid outlet, see Fig. 4P) compared to lean conditions $\left(0.20 \mathrm{~mol} \mathrm{~mol}^{-1}\right.$ at MBC liquid outlet). One might therefore decide to use a different design strategy in terms of flash gas utilization or reprocessing for the lean and semi-lean modes of operation.

\subsection{Improved Semi-lean Process to Meet Sales Gas Specification}

The pilot plant experiments in Sec. 3 demonstrate that sales gas specification with less than 2 $3 \mathrm{~mol} \%$ of $\mathrm{CO}_{2}$ can be achieved under both lean and semi-lean conditions, yet with the semi-lean operation consuming $80 \%$ less energy compared to lean operation. However, this comparison might be misleading as these experiments were all conducted with the same solvent flowrate of $275 \mathrm{~L} \mathrm{~h}^{-1}$. To allow for a fairer comparison, a case study is conducted here for treating $75 \mathrm{~kg} \mathrm{~h}^{-1}$ of sour $\mathrm{NG}$ with a target $\mathrm{CO}_{2}$ purity of $1.5 \mathrm{~mol} \%$ by adjusting the solvent flowrate.

- The configuration of the lean amine process follows the flowsheet in Fig. 3, yet without the internal amine recycle to the stripper column (cf. dashed line in Fig. 11). In order to achieve a $\mathrm{CO}_{2}$ loading of $0.01 \mathrm{~mol} \mathrm{~mol}^{-1}$ at the $\mathrm{MBC}$ liquid inlet, the reboiler temperature is set to $403 \mathrm{~K}$.

- A modified configuration is adopted for the semi-lean amine process, whereby the stripper column and reboiler are replaced with a low-pressure flash drum and heater, respectively. The corresponding flowsheet is depicted in Fig. 7. The target $\mathrm{CO}_{2}$ loading of $0.23 \mathrm{~mol} \mathrm{~mol}^{-1}$ in the solvent feed to the MBC is achieved by imposing a temperature of $376 \mathrm{~K}$ in the flash drum heater.

Most of the composition, temperature and pressure specifications in Table 2 remain in effect in both processes. The modified or extra specifications are reported in Table 3 together with several KPI predictions for each process configuration.

The solvent flowrate in the lean amine process $\left(106 \mathrm{~L} \mathrm{~h}^{-1}\right)$ is $30 \%$ lower than in the semi-lean process $\left(150 \mathrm{~L} \mathrm{~h}^{-1}\right)$ in order to meet the same $\mathrm{CO}_{2}$ purity of $1.5 \mathrm{~mol} \%$. This is mainly due to the higher $\mathrm{CO}_{2}$ absorption capacity of the fully-regenerated solvent. The corresponding solvent-toabsorbed- $\mathrm{CO}_{2}$ ratios of $0.54 \mathrm{~m}^{3} \mathrm{kmol}^{-1}$ in the lean process and $0.77 \mathrm{~m}^{3} \mathrm{kmol}^{-1}$ in the semi-lean process are at the lower end of the range $0.6-1.1 \mathrm{~m}^{3} \mathrm{kmol}^{-1}$ that is typical of conventional packed columns [41-43].

A lower solvent flowrate in the lean amine process translates into a lower energy consumption in all of the pumps. Nevertheless, the total process duty of the lean process $(13.7 \mathrm{~kW})$ remains $16 \%$ higher compared to the semi-lean process $(11.6 \mathrm{~kW})$. This is attributed to: (i) the higher reboiler temperature needed to fully regenerate the solvent in the lean process; and (ii) the greater cooling duty in the lean solution cooler since the temperature of the solvent leaving the stripper column is higher in the lean process despite the heat integration provided by the lean-rich heat exchanger.

335 A breakdown of the plant-wide energy consumption by main equipment is shown in Fig. 8 for both the lean and semi-lean processes. The reboiler duty makes up the largest share with about $40-49 \%$ of the plant-wide energy consumption, which is consistent with the figures from conventional amine-based processes [8, 28]. By contrast, the pumping energy required by the $\mathrm{MBC}$ is only a few percentage points. The lean solution cooler and amine chiller come second and third, with respective shares of $29-36 \%$ and $9-16 \%$. This analysis suggests that the process duty could be further reduced by feeding the regenerated solvent to the $\mathrm{MBC}$ at a temperature of 


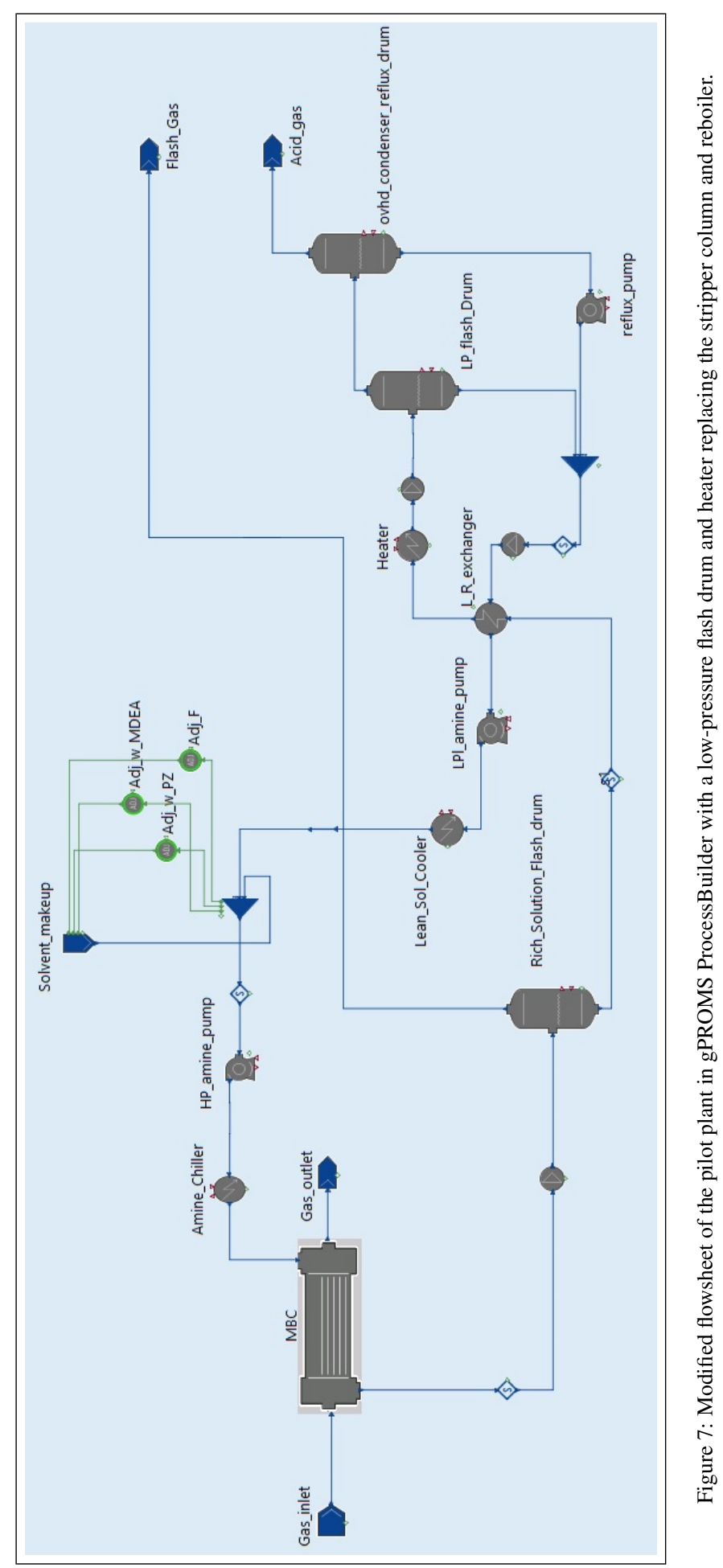

15 
Table 3: Modified operating conditions and performance indicators in the pilot experimental setup in order to achieve a $\mathrm{CO}_{2}$ purity of $1.5 \mathrm{~mol} \%$ under lean and semi-lean operations.

\begin{tabular}{lrr}
\hline & $\begin{array}{c}\text { Lean } \\
\text { process }\end{array}$ & $\begin{array}{c}\text { Semi-lean } \\
\text { process }\end{array}$ \\
\hline Absorption - NG sweetening & & \\
MBC tube, inlet gas temperature $(\mathrm{K})$ & 298 & 298 \\
$\quad$ outlet gas $\mathrm{CO}_{2}$ composition $(\mathrm{mol} \%)$ & 1.5 & 1.5 \\
MBC shell, inlet solvent flowrate $\left(\mathrm{L}^{-1}\right)$ & 106 & 150 \\
$\quad$ inlet solvent temperature $(\mathrm{K})$ & 303 & 303 \\
$\quad$ inlet $\mathrm{CO}_{2}$ loading in solvent $\left(\mathrm{mol} \mathrm{mol}^{-1}\right)$ & 0.01 & 0.23 \\
\hline Desorption - Solvent regeneration & & \\
Reboiler temperature $(\mathrm{K})$ & 403 & 376 \\
Amine chiller, outlet temperature $(\mathrm{K})$ & 303 & 303 \\
\hline Performance indicators & & \\
LHV of flash gas $\left(\mathrm{MJ} \mathrm{kg}{ }^{-1}\right)$ & 48.4 & 45.6 \\
Amine loss with treated gas $\left(\mathrm{mg} \mathrm{Sm}^{-3}\right)$ & 7.9 & 8.4 \\
$\quad$ acid gas $\left(\mathrm{mg} \mathrm{Sm}^{-3}\right)$ & 53.1 & 40.6 \\
$\quad$ flash gas $\left(\mathrm{mg} \mathrm{Sm}^{-3}\right)$ & 0.7 & 4.2 \\
Total process duty $\left(\mathrm{kW}^{-3}\right)$ & 13.7 & 11.6 \\
\hline
\end{tabular}

$318 \mathrm{~K}$, thereby removing the amine chiller. This process modification would furthermore reduce the physical footprint of the whole process and it is adopted in the final scale-up study conducted in Sec. 5 below. However, we note that removing the amine chiller could also have adverse consequences since a higher solvent temperature will raise the amine vapor pressure, resulting in increased amine losses. A higher solvent temperature will also increase the outlet gas temperature and in turn the water content of the gas, thereby increasing the loading of downstream dehydration equipment [44].

By and large, the semi-lean configuration presents a better intensification potential than its lean counterpart to achieve sales gas specification since it reduces both the energy consumption and the physical footprint of the process. The predicted amine losses under this mode of operation are also comparable to those of the lean process (see Table 3), while its only downside would be a reduction in LHV of the flash gas that could prevent its use in a conventional combustion turbine. It is expected that these benefits will translate into a significant reduction in capital and operating expenditures compared with the lean mode of operation in a commercial-scale sweetening process.

\section{Model-based Scale-up of a Commercial Semi-lean Process for Natural Gas Sweetening}

The final section investigates the design of a commercial process by leveraging knowledge acquired in this paper and its companion [31] from both the experimental and modeling studies. We consider an industrially-relevant scenario, whereby 233 MMSCFD of sour NG with a $\mathrm{CO}_{2}$ content of $24 \mathrm{~mol} \%$ need to be sweetened to $6.5 \mathrm{~mol} \%$ before sending the gas onshore for further processing. The focus is on the semi-lean process (Fig. 7), which has shown superior performance in the pilot-plant experiments and is also supported by the modeling results. 


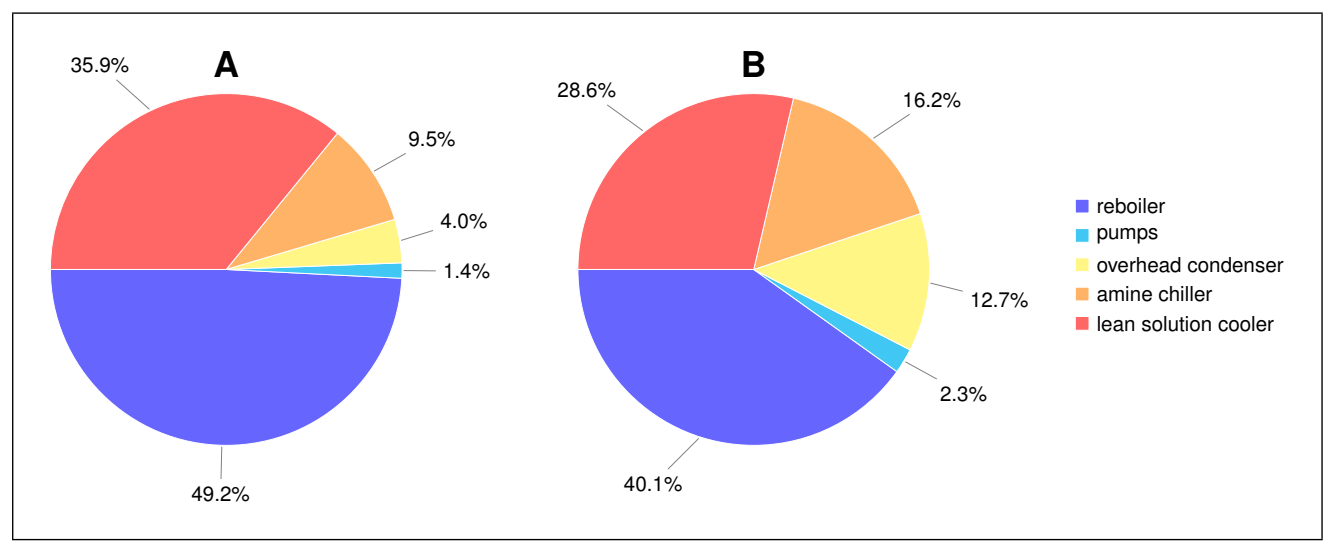

Figure 8: Breakdown of the plant-wide energy consumption by main equipment. A: lean amine process using a stripper column. B: semi-lean amine process using a low-pressure flash drum.

\subsection{Commercial Process Specifications}

We assume that the high-pressure MBC cartridges are packed with the same PTFE hollow fibers and have the same geometry (radius: $0.115 \mathrm{~m}$, length: $2.3 \mathrm{~m}$ ) as in the lab and pilotplant setups [31, Table 2], yet without the steel tube insert (compare Sec. 2.1). The cartridges are assembled into MBC modules as illustrated in Fig. 9. and a number of these modules are then operated in parallel as a strategy to scale up the throughput-this modular configuration 370 is adopted in an effort to limit the number of high-pressure vessels in the process. In order to determine how many modules are needed for treating 233 MMSCFD of NG, we use the average absorption flux of $7.1 \mathrm{~mol} \mathrm{~m}^{-2} \mathrm{~h}^{-1}$ that was measured under the same NG composition and semilean conditions in the lab setup [31, Fig. 7B-C]. The corresponding total membrane area is estimated to be $287000 \mathrm{~m}^{2}$, which requires in excess of $2120 \mathrm{MBC}$ cartridges and thus $69 \mathrm{MBC}$

375 modules. The estimated total volume and weight for these MBC modules are $320 \mathrm{~m}^{3}$ and 830 ton, respectively a $50 \%$ and $10 \%$ reduction against a state-of-the-art packed column designed by PETRONAS for similar gas flowrate, solvent composition and $\mathrm{CO}_{2}$ abatement; check Ref. [45] for a detailed comparison of MBC vs. packaged column in terms of volume footprint. In addition to this large intensification factor, the solvent flowrate $\left(1675 \mathrm{~m}^{3} \mathrm{~h}^{-1}\right)$ is minimized in order to

380 meet the desired $\mathrm{CO}_{2}$ purity $(6.5 \mathrm{~mol} \%)$, so that the energy required to regenerate the solvent is also minimized. The specifications in the $\mathrm{CO}_{2}$ absorption section are summarized in the top part of Table 4

Following the recommendations in Sec. 4, we also depart from the pilot-plant setup by (i) removing the amine chiller to reduce the process duty and the physical footprint, and (ii) reducing the temperature of the overhead condenser to mitigate the solvent evaporative losses with the acid gas. The new set of specifications in the solvent regeneration section is reported in the bottom part of Table 4.

\subsection{Commercial Process Performance}

A set of KPIs for the scale-up semi-lean MBC process are listed in Table 5. The variation ranges for these KPIs correspond to a $\pm 5 \%$ change in the Henry constants of $\mathrm{N}_{2} \mathrm{O}, \mathrm{CH}_{4}, \mathrm{C}_{2} \mathrm{H}_{6}$ and $\mathrm{C}_{3} \mathrm{H}_{8}$ in amine solvent, which is consistent with the predicted uncertainty in the regressions 
Table 4: Specifications of commercial semi-lean process for NG sweetening.

\begin{tabular}{|c|c|}
\hline \multicolumn{2}{|l|}{ Absorption - NG sweetening } \\
\hline $\mathrm{MBC}$ tube, inlet gas composition $\mathrm{CO}_{2} / \mathrm{CH}_{4} / \mathrm{C}_{2} \mathrm{H}_{6} / \mathrm{C}_{3} \mathrm{H}_{8}(\mathrm{~mol} \%)$ & $24 / 73 / 2 / 1$ \\
\hline inlet gas flowrate $\left(\mathrm{kmol} \mathrm{h}^{-1}\right)$ & 11630 \\
\hline inlet gas pressure $(\mathrm{kPa})$ & 5400 \\
\hline inlet gas temperature $(\mathrm{K})$ & 298 \\
\hline MBC shell, inlet solvent composition MDEA / PZ (wt\%) & $39 / 5$ \\
\hline inlet solvent flowrate $\left(\mathrm{m}^{3} \mathrm{~h}^{-1}\right)$ & 1675 \\
\hline inlet solvent temperature $(\mathrm{K})$ & 318 \\
\hline outlet solvent pressure $(\mathrm{kPa})$ & 5430 \\
\hline MBC cartridge, inner radius (m) & 0.115 \\
\hline number of fibers & 17,000 \\
\hline MBC module, number of cartridges & 31 \\
\hline inner radius $(\mathrm{m})$ & 0.8 \\
\hline Number of MBC modules & 69 \\
\hline \multicolumn{2}{|l|}{ Desorption - Solvent regeneration } \\
\hline Rich solution drum, pressure $(\mathrm{kPa})$ & 911 \\
\hline Solvent regeneration flash drum, pressure $(\mathrm{kPa})$ & 258 \\
\hline heater, temperature $(\mathrm{K})$ & 377 \\
\hline Overhead condenser, outlet temperature $(\mathrm{K})$ & 318 \\
\hline Reflux pump, outlet pressure $(\mathrm{kPa})$ & 258 \\
\hline Lean-rich exchanger cold stream, outlet temperature $(\mathrm{K})$ & 364 \\
\hline outlet pressure $(\mathrm{kPa})$ & 368 \\
\hline hot stream, outlet pressure $(\mathrm{kPa})$ & 233 \\
\hline LP amine pump, outlet pressure $(\mathrm{kPa})$ & 711 \\
\hline Lean solution cooler, outlet temperature $(\mathrm{K})$ & 318 \\
\hline pressure drop $(\mathrm{kPa})$ & 35 \\
\hline HP amine HP pump, outlet pressure ( $\mathrm{kPa})$ & 5430 \\
\hline
\end{tabular}




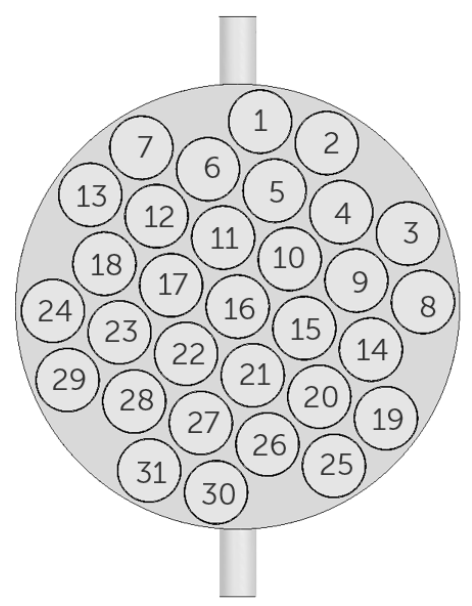

Figure 9: Cross-section of commercial-scale MBC module with radius of $0.8 \mathrm{~m}$, containing 31 smaller MBC cartridges with radius of $0.115 \mathrm{~m}$ each.

Table 5: Key performance indicators of commercial semi-lean process for $\mathrm{NG}$ sweetening. The variation ranges are calculated for a $\pm 5 \%$ change in the Henry constants of $\mathrm{N}_{2} \mathrm{O}, \mathrm{CH}_{4}, \mathrm{C}_{2} \mathrm{H}_{6}$ and $\mathrm{C}_{3} \mathrm{H}_{8}$ in amine solvent.

\begin{tabular}{lrc}
\hline Performance indicator & Nominal value & Variation range \\
\hline $\mathrm{CO}_{2}$ purity of treated gas $(\mathrm{mol} \%)$ & 6.4 & $6.2-6.6$ \\
$\mathrm{CO}_{2}$ absorption flux $\left(\mathrm{mol} \mathrm{m}^{-2} \mathrm{~h}^{-1}\right)$ & 7.6 & $7.5-7.7$ \\
Solvent-to-absorbed- $\mathrm{CO}_{2}$ ratio $\left(\mathrm{m}^{3} \mathrm{kmol}^{-1}\right)$ & 0.76 & $0.75-0.78$ \\
Reboiler energy per $\mathrm{CO}_{2}$ removed $\left(\mathrm{GJ} \mathrm{ton}^{-1}\right)$ & 2.20 & $2.18-2.21$ \\
Recovered hydrocarbons in flash gas $\left(\right.$ ton h$\left.^{-1}, \%\right)$ & $1.04(82 \%)$ & $0.98(81 \%)-1.10(83 \%)$ \\
$\mathrm{LHV}$ of flash gas $\left(\mathrm{MJ} \mathrm{kg}^{-1}\right)$ & 29.5 & $29.1-29.8$ \\
Amine loss per $\mathrm{CO}_{2}$ removed $\left(\mathrm{kg} \mathrm{ton}^{-1}\right)$ & 0.270 & $0.268-0.272$ \\
\hline
\end{tabular}

embedded in the MBC model [31, Figs. 5-6]. The effect of this uncertainty on the KPIs is rather small overall. First of all, it can be checked that the $\mathrm{CO}_{2}$ concentration in the treated gas meets the desired target of $6.5 \mathrm{~mol} \%$. The predicted $\mathrm{CO}_{2}$ absorption flux $\left(7.6 \mathrm{~mol} \mathrm{~m}^{-2} \mathrm{~h}^{-1}\right)$ is $7 \%$ higher than the same flux measured in the lab setup $\left(7.1 \mathrm{~mol} \mathrm{~m}^{-2} \mathrm{~h}^{-1}\right)$, a difference caused by the higher solvent temperature in the MBC after removing the amine chiller. Such an increase in the $\mathrm{CO}_{2}$ absorption flux at higher solvent temperature was also observed experimentally [19. 31]. The predicted solvent-to-absorbed- $\mathrm{CO}_{2}$ ratio $\left(0.76 \mathrm{~m}^{3} \mathrm{kmol}^{-1}\right)$ is comparable to the pilotscale process (Sec. 4.3) and again in the lower range of typical values for conventional packed columns [41-43]. Furthermore, the reduction in reboiler energy per $\mathrm{CO}_{2}$ removed $\left(2.2 \mathrm{GJ}_{\text {ton }}{ }^{-1}\right)$ compared to conventional amine treating processes (2.4-4.2 $\mathrm{GJ}^{-1} \mathrm{ton}^{-1}$, see [46-48]) is mostly attributed to operating the MBC process under semi-lean conditions (Sec. 4.3).

The predicted hydrocarbon recovery of over $80 \%$ with the flash gas is in agreement with the pilot-plant results (Fig. 6). Though the corresponding LHV below $30 \mathrm{MJ} \mathrm{kg}^{-1}$ indicates a much higher $\mathrm{CO}_{2}$ concentration in the flash gas compared to the pilot plant, which results from the higher $\mathrm{CO}_{2}$ content in the gas feed and consequently a richer amine $\left(0.59 \mathrm{~mol} \mathrm{~mol}^{-1}\right)$. A scenario analysis reveals that the LHV could be raised to $37 \mathrm{MJ} \mathrm{kg}^{-1}$ upon increasing the flash 
drum pressure to $1500 \mathrm{kPa}$, but this would then lower the hydrocarbon recovery to below $70 \%$. The variation range in the recovered hydrocarbon flow rate $\left(0.98-1.10\right.$ ton h$\left.^{-1}\right)$ is on a par with the $\pm 5 \%$ uncertainty imposed on the Henry constant of the light hydrocarbons. A quick estimate of the corresponding annual cost savings is in the range of US\$543k-626k, assuming 8,000 operating hours per year and an energy cost of US $\varnothing 0.24 \mathrm{MJ}^{-1}$ [49]. In turn, this estimate could feed into an economic assessment to decide between sweetening the flash gas and using it in a gas turbine, recompressing and returning the flash gas to the MBC gas inlet, or simply disposing 415 of the flash gas by flaring.

By and large, the scaled-up semi-lean MBC process shows a promising intensification potential compared to conventional amine-based processes in order to meet sales gas specification, via: (i) reducing the physical volume of the absorption section and substituting the stripper column by a flash drum; and (ii) reducing the reboiler energy per amount of $\mathrm{CO}_{2}$ removed and thus the overall process duty. The ability to recover the hydrocarbons dissolved in the enriched amine could also contribute to generating extra energy or revenue for the gas sweetening plant.

\section{Conclusions}

This paper has presented a model-based assessment of a natural gas sweetening process combining a high-pressure $\mathrm{MBC}$ with the solvent regeneration. The plant-wide model builds upon the $\mathrm{MBC}$ model developed in the companion paper [31] and is capable of quantitative predictions of a broad set of KPIs, including the $\mathrm{CO}_{2}$ and hydrocarbon absorption by the amine solvent in the $\mathrm{MBC}$, the solvent evaporative losses across the process, the recovery of dissolved hydrocarbons from the enriched amine, and the process duty and its breakdown between units. Its predictive capability has been tested against experimental data from a pilot plant in Malaysia for a wide 430 range of $\mathrm{CO}_{2}$ loadings in the amine solvent, showing an excellent agreement in terms of $\mathrm{CO}_{2}$ outlet purity and energy consumption.

A detailed model-based investigation has compared two configurations of the amine regeneration section of the plant, whereby the amine solvent is either fully regenerated using a conventional stripper column leading to lean operation, or partially regenerated in a low-pressure flash

435 drum resulting in semi-lean operation. Only the former can meet LNG specification and achieve deep $\mathrm{CO}_{2}$ removal to ppm levels, but semi-lean operation was shown to be suitable for bulk $\mathrm{CO}_{2}$ removal in order to meet sales gas specification. In particular, it was found that the semi-lean process configuration can reduce the overall energy consumption significantly and does not increase the solvent evaporative losses in either the adsorption or regeneration section of the plant.

440 A possible drawback of the semi-lean mode of operation is the higher $\mathrm{CO}_{2}$ content of the flash gas, which reduces its LHV and could prevent its direct use in a gas turbine.

In the final part of the paper, the scale-up of a commercial semi-lean $\mathrm{MBC}$ process has been conducted for sweetening of an industrial natural gas stream with $24 \mathrm{~mol} \% \mathrm{CO}_{2}$ down to $6.5 \mathrm{~mol} \%$. This case study provides compelling evidence of the large intensification potential ${ }_{445}$ of semi-lean MBC operations compared to conventional amine-based processes. A key benefit, besides the smaller volume footprint of both the absorption and stripping sections, is the reduction in energy consumption for the amine regeneration. This reduction is enabled by operating the $\mathrm{MBC}$ with a semi-lean amine and at a lower $\mathrm{L} / \mathrm{G}$ ratio than conventional packed columns, thereby highlighting the need to assess NG sweetening in a plant-wide manner. A simple economic assessment has also quantified the extra income expected to be generated from recovering the dissolved hydrocarbons in the amine solvent. 
Future work will consider the application of systematic model-based optimisation techniques to further improve the design and operation of commercial MBC modules and processes. It will also be interesting to investigate the performance and intensification potential of processes that use the $\mathrm{MBC}$ technology both for the $\mathrm{CO}_{2}$ absorption and desorption.

Acknowledgments. The authors gratefully acknowledge PETRONAS for financial support and for providing the experimental data through the PETRONAS Centre for Engineering of Multiphase Systems at Imperial College London.

\section{References}

[1] TC Energy. Gas Quality Specifications, 2016. URL http://www.tccustomerexpress.com/docs/Gas_ Quality_Specifications_Fact_Sheet.pdf

[2] N. Boucif, J. P. Corriou, D. Roizard, and E. Favre. Carbon dioxide absorption by monoethanolamine in hollow fiber membrane contactors: A parametric investigation. AIChE Journal, 58(9):2843-2855, 2012. doi: 10.1002/aic. 12791.

465 [3] K. A. Hoff. Modeling and Experimental Study of Carbon Dioxide Absorption in a Membrane Contactor. PhD thesis, Norwegian University of Science and Technology (NTNU), Throndheim, 2003.

[4] S. Paul, A. K. Ghoshal, and B. Mandal. Removal of $\mathrm{CO}_{2}$ by single and blended aqueous alkanolamine solvents in hollow-fiber membrane contactor: Modeling and simulation. Industrial E Engineering Chemistry Research, 46(8): 2576-2588, 2007. doi: 10.1021/ie061476f.

[5] X. He and M. B. Hägg. Membranes for environmentally friendly energy processes. Membranes, 2(4):706-726, 2012. doi: 10.3390/membranes2040706.

[6] Yuan Zhang and Rong Wang. Gas-liquid membrane contactors for acid gas removal: Recent advances and future challenges. Current Opinion in Chemical Engineering, 2(2):255-262, 2013. doi: 10.1016/j.coche.2013.03.008.

[7] A. B. Rao and E. S. Rubin. A technical, economic, and environmental assessment of amine-based $\mathrm{CO}_{2}$ capture technology for power plant greenhouse gas control. Environmental Science E Technology, 36(20):4467-4475, 2002. doi: 10.1021/es0158861.

[8] N. MacDowell, N. Florin, A. Buchard, J. Hallett, A. Galindo, G. Jackson, C. S. Adjiman, C. K. Williams, N. Shah, and P. Fennell. An overview of $\mathrm{CO}_{2}$ capture technologies. Energy E Environmental Science, 3(11):1645-1669, 2010. doi: 10.1039/c004106h.

[9] H. A. Rangwala. Absorption of carbon dioxide into aqueous solutions using hollow fiber membrane contactors. Journal of Membrane Science, 112(2):229-240, 1996. doi: 10.1016/0376-7388(95)00293-6.

[10] A. Gabelman and S.-T. Hwang. Hollow fiber membrane contactors. Journal of Membrane Science, 159(1-2): 61-106, 1999. doi: 10.1016/S0376-7388(99)00040-X.

[11] A. Mansourizadeh and A. F. Ismail. Hollow fiber gas-liquid membrane contactors for acid gas capture: A review. Journal of Hazardous Materials, 171:38-53, 2009. doi: 10.1016/j.jhazmat.2009.06.026.

[12] E. Favre. Membrane processes and postcombustion carbon dioxide capture: Challenges and prospects. Chemical Engineering Journal, 171(3):782-793, 2011. doi: 10.1016/j.cej.2011.01.010.

[13] S. D. Bazhenov and E. S. Lyubimova. Gas-liquid membrane contactors for carbon dioxide capture from gaseous streams. Petroleum Chemistry, 56(10):889-914, 2016. doi: 10.1134/S0965544116100029.

490 [14] P. Luis, T. Van Gerven, and B. Van der Bruggen. Recent developments in membrane-based technologies for $\mathrm{CO}_{2}$ capture. Progress in Energy and Combustion Science, 38(3):419-448, 2012. doi: 10.1016/j.pecs.2012.01.004.

[15] M. Al-Marzouqi, M. El-Naas, S. Marzouk, and N. Abdullatif. Modeling of chemical absorption of $\mathrm{CO}_{2}$ in membrane contactors. Separation $\mathcal{E}$ Purification Technology, 62(3):499-506, 2008. doi: 10.1016/j.seppur.2008.02.009.

[16] M. Rezakazemi, Z. Niazi, M. Mirfendereski, S. Shirazian, T. Mohammadi, and A. Pak. CFD simulation of natural gas sweetening in a gas-liquid hollow-fiber membrane contactor. Chemical Engineering Journal, 168(3):12171226, 2011. doi: 10.1016/j.cej.2011.02.019.

[17] K. A. Hoff and H. F. Svendsen. Membrane contactors for $\mathrm{CO}_{2}$ absorption - Application, modeling and mass transfer effects. Chemical Engineering Science, 116:331-341, 2014. doi: 10.1016/j.ces.2014.05.001.

[18] R. Faiz and M. H. Al-Marzouqi. $\mathrm{CO}_{2}$ removal from natural gas at high pressure using membrane contactors: Model validation and membrane parametric studies. Journal of Membrane Science, 365(1-2):232-241, 2010. doi: 10.1016/j.memsci.2010.09.004.

[19] V. C. Quek, N. Shah, and B. Chachuat. Modeling for design and operation of high-pressure membrane contactors in natural gas sweetening. Chemical Engineering Research $\mathcal{E}$ Design, 132:1005-1019, 2018. doi: 10.1016/j.cherd. 2018.01.033. 
[20] N. Goyal, S. Suman, and S. K. Gupta. Mathematical modeling of $\mathrm{CO}_{2}$ separation from gaseous-mixture using a hollow-fiber membrane module: Physical mechanism and influence of partial-wetting. Journal of Membrane Science, 474:64-82, 2015. doi: 10.1016/j.memsci.2014.09.036.

[21] S.-H. Yeon, K.-S. Lee, B. Sea, Y.-I. Park, and K.-H. Lee. Application of pilot-scale membrane contactor hybrid system for removal of carbon dioxide from flue gas. Journal of Membrane Science, 257(1):156-160, 2005. doi: 10.1016/j.memsci.2004.08.037.

[22] S.-P. Yan, M.-X. Fang, W.-F. Zhang, S.-Y. Wang, Z.-K. Xu, Z.-Y. Luo, and K.-F. Cen. Experimental study on the separation of $\mathrm{CO}_{2}$ from flue gas using hollow fiber membrane contactors without wetting. Fuel Processing Technology, 88(5):501-511, 2007. doi: 10.1016/j.fuproc.2006.12.007.

[23] Y. Lee, R. D. Noble, B.-Y. Yeom, Y.-I. Park, and K.-H. Lee. Analysis of $\mathrm{CO}_{2}$ removal by hollow fiber membrane contactors. Journal of Membrane Science, 194(1):57-67, 2001. doi: 10.1016/S0376-7388(01)00524-5.

[24] P. Kosaraju, A. S. Kovvali, A. Korikov, and K. K. Sirkar. Hollow fiber membrane contactor based $\mathrm{CO}_{2}$ absorptionstripping using novel solvents and membranes. Industrial $\mathcal{F}$ Engineering Chemistry Research, 44(5):1250-1258, 2005. doi: $10.1021 / \mathrm{ie} 0495630$.

[25] K. Simons, K. Nijmeijer, and M. Wessling. Gas-liquid membrane contactors for $\mathrm{CO}_{2}$ removal. Journal of Membrane Science, 340:214-220, 2009. doi: 10.1016/j.memsci.2009.05.035.

[26] S.-J. Kim, A. Park, S.-E. Nam, Y.-I. Park, and P. S. Lee. Practical designs of membrane contactors and their performances in $\mathrm{CO}_{2} / \mathrm{CH}_{4}$ separation. Chemical Engineering Science, 155:239-247, 2016. doi: 10.1016/j.ces. 2016.08.018

[27] D Pakšiová, M Fikar, and S Skogestad. Modeling of carbon dioxide removal using membrane contactors. 2016 Cybernetics $\mathcal{E}$ Informatics (KE्EI), pages 1-6, 2016. doi: 10.1109/CYBERI.2016.7438596.

[28] A. M. Cormos and I. M. Daraban. Dynamic modeling and validation of amine-based $\mathrm{CO}_{2}$ capture plant. Applied Thermal Engineering, 74:202-209, 2015. doi: 10.1016/j.applthermaleng.2013.12.045.

[29] Z. P. Chan, L. Li, G. Kang, N. Ab Manan, Y. Cao, and T. Wang. Deep $\mathrm{CO}_{2}$ removal using high pressure membrane contactors with low liquid-to-gas ratio. Chemical Engineering Research $\mathcal{F}$ Design, 153:528-536, 2020. doi: 10.1016/j.cherd.2019.11.017.

[30] Process Systems Enterprise Ltd. gPROMS. url: www.psenterprise.com/gproms, 1997-2019.

[31] V. C. Quek, N. Shah, and B. Chachuat. Plant-wide assessment of high-pressure membrane contactors in natural gas sweetening - Part I: Model development. Submitted for publication, 2020.

[32] R Billet and M Schultes. Prediction of mass transfer columns with dumped and arranged packings. Chemical Engineering Research $\mathcal{E}$ Design, 77(6):498-504, 1999. doi: 10.1205/026387699526520.

[33] C. F. Alie. $\mathrm{CO}_{2}$ capture with MEA: Integrating the absorption process and steam cycle of an existing coal-fired power plant. Master's thesis, University of Waterloo, Ontario, Canada, 2004.

[34] B. Xu, H. Gao, M. Chen, Z. Liang, and R. Idem. Experimental study of regeneration performance of aqueous $\mathrm{N}, \mathrm{N}$-diethylethanolamine solution in a column packed with Dixon ring random packing. Industrial $\mathcal{E}$ Engineering Chemistry Research, 55(31):8519-8526, 2016. doi: 10.1021/acs.iecr.6b00936.

[35] E. Teletzke and B. Madhyani. Minimise amine losses in gas and liquid treating. Petroleum Technology Quaterly Gas, pages 35-45, 2018.

[36] D. W. Bailey and P. H. M. Feron. Post-combustion decarbonisation processes. Oil and Gas Science E Technology, 60(3):461-474, 2005. doi: 10.2516/ogst:2005028.

37] J. J. Carroll, J. Maddocks, and A. E. Mather. The solubility of hydrocarbons in amine solutions. Laurance Reid Gas Conditioning Conference, pages 44-64, 1998

[38] U.S. Department of Energy. Appendix A: Lower and higher heating values of gas, liquid and solid fuels. In Biomass Energy Data Book, September 2011.

[39] M. Welch and B. Igoe. The impact of carbon dioxide and nitrogen in fuel gas on gas turbine operation. In Offshore Technology Conference, Rio de Janeiro, Brazil, 2015. doi: 10.4043/26347-MS

[40] ISO 6976. Natural gas - Calculation of calorific values, density, relative density and Wobbe index from composition. 3rd edition, 2016

[41] S.-Y. Park, B.-M. Min, J.-S. Lee, S.-C. Nam, K.-H. Han, and J.-S. Hyun. Absorption characteristic of continuous $\mathrm{CO}_{2}$ absorption process. Preprints of Papers - American Chemical Society, Division of Fuel Chemistry, 49(1), 2004.

[42] F. Rezazadeh, W. F. Gale, M. Akram, K. J. Hughes, and M. Pourkashanian. Performance evaluation and optimisation of post combustion $\mathrm{CO}_{2}$ capture processes for natural gas applications at pilot scale via a verified rate-based model. International Journal of Greenhouse Gas Control, 53:243-253, 2016. doi: 10.1016/j.ijggc.2016.08.003.

[43] J. Gaspar, Gladis A., J. M. Woodley, K. Thomsen, N. von Solms, and P. L. Fosbøl. Rate-based modelling and validation of a pilot absorber using MDEA enhanced with carbonic anhydrase (CA). Energy Procedia, 114:707718, 2017. doi: 10.1016/j.egypro.2017.03.1213.

[44] M. I. Stewart. Chapter nine - gas sweetening. In Surface Production Operations, volume 2, pages 433-539. Gulf Professional Publishing, Boston, 3rd edition edition, 2014. doi: 10.1016/B978-0-12-382207-9.00009-3. 


\section{Nomenclature}

\section{Acronyms}

HFM hollow-fiber membrane

KPI key performance indicator

LHV lower heating value

MBC membrane contactor

MDEA methyldiethanolamine

MFC mass-flow controller
MMSCFD million standard cubic feet per day

NG natural gas

PTFE polytetrafluoroethylene

$\mathrm{PZ} \quad$ piperazine

$\mathrm{Sm}^{3} \quad$ standard cubic meter (at $15^{\circ} \mathrm{C}, 1$ atm)

[45] K. A. Hoff and H. F. Svendsen. $\mathrm{CO}_{2}$ absorption with membrane contactors vs. packed absorbers - Challenges and opportunities in post combustion capture and natural gas sweetening. Energy Procedia, 37(1876):952-960, 2013. doi: 10.1016/j.egypro.2013.05.190.

[46] N. Dave, T. Do, G. Puxty, R. Rowland, P. H. M. Feron, and M. I. Attalla. $\mathrm{CO}_{2}$ capture by aqueous amines and aqueous ammonia - A comparison. Energy Procedia, 1(1):949-954, 2009. doi: 10.1016/j.egypro.2009.01.126.

[47] U. Liebenthal, D. Di D. Pinto, J. G. M.-S. Monteiro, H. F. Svendsen, and A. Kather. Overall process analysis and optimisation for $\mathrm{CO}_{2}$ capture from coal fired power plants based on phase change solvents forming two liquid phases. Energy Procedia, 37:1844-1854, 2013. doi: 10.1016/j.egypro.2013.06.064.

[48] J. Narku-Tetteh, D. B. Afari, J. Coker, and R. Idem. Evaluation of the roles of absorber and desorber catalysts in the heat duty and heat of $\mathrm{CO}_{2}$ desorption from butylethanolamine-2-amino-2-methyl-1-propanol and monoethanolamine-methyldiethanolamine solvent blends in a bench-scale $\mathrm{CO}_{2}$ capture pilot plant. Energy $\mathcal{E} \mathrm{Fu}-$ els, 32(9):9711-9726, 2018. doi: 10.1021/acs.energyfuels.8b02205.

[49] U.S. Energy Information Administration. Henry Hub Natural Gas Spot Price, 2019. URL: https://www.eia.gov/dnav/ng/hist/rngwhhdD.htm. 